\title{
Spatio-temporal variability of droughts in Bolivia: 1955-2012
}

Vicente-Serrano, S.M. ${ }^{1}$, Chura, O. ${ }^{2}$, López-Moreno, J.I. ${ }^{1}$, Azorin-Molina, C. ${ }^{1}$, Sanchez-Lorenzo, A. ${ }^{1,3}$, Aguilar, E. ${ }^{4}$, Moran-Tejeda, E. ${ }^{1}$, Trujillo, F. ${ }^{2}$, Martínez, R. ${ }^{5}$, Nieto, J.J. ${ }^{5}$

${ }^{1}$ Instituto Pirenaico de Ecología, Consejo Superior de Investigaciones Científicas (IPE-CSIC), Zaragoza, Spain; ${ }^{2}$ Servicio Nacional de Meteorología (SENAMHI), La Paz, Bolivia ${ }^{3}$ Department of Physics, University of Girona, Spain, ${ }^{4}$ Universitat Rovira i Virgili, Tarragona, Spain ${ }^{5}$ Centro Internacional para la Investigación del Fenómeno de El Niño (CIIFEN), Guayaquil, Ecuador.

* Corresponding author: svicen@ipe.csic.es

Abstract: In this study the spatio-temporal variability and trends of droughts across Bolivia between 1955 and 2012 were investigated using two climate drought indices: the Standardized Precipitation Index (SPI), which is based on precipitataion data, and the Standardized Precipitation Evapotranspiration Index (SPEI), which is based on the difference between the precipitation and the reference evapotranspiration (ETo). We found that average drought conditions across the country showed a temporal behavior mainly characterized by decadal variations. The spatial pattern of drought evolution showed marked differences between the Amazonian region and the Bolivian Altiplano. Both regions showed different drought periods, a lower frequency of drought variability in the Amazon region and trends toward drier conditions in the Altiplano, mainly due to a higher atmospheric water demand as a consequence of increased ETo. We also showed that inclusion of ETo, obtained from maximum and minimum temperature records, increased the spatial heterogeneity of the drought evolution in relation to the evolution observed when only precipitation droughts were considered. The SPEI, the calculation of which includes precipitation and ETo, indicated intensification in drought severity in the last years analyzed relative to the pattern found when precipitation droughts alone were considered, and also indicated an increase in the magnitude and duration of drought events. The potential for increasing drought conditions under various climate change scenarios is discussed. 
Key-words: South America, Standardized Precipitation Index (SPI), Standardized Precipitation Evapotranspiration Index (SPEI), Altiplano, Amazon, trends

\section{Introduction}

Drought causes major losses in agriculture (Potop et al., 2012; Hunt et al., 2014), and damages natural ecosystems and forestry (Bresshears et al., 2005). It may lead to desertification and degradation of soils (Nicholson et al., 1998; Vicente-Serrano et al., 2012) and social disruption (Morales et al., 2000). Droughts are especially important in regions where economic activities are highly dependent on water resources, and particularly affect nations heavily reliant on agriculture, including both subsistence and highly intensive and high technology agricultural practices. A number of indigenous communities in South America base their economies on livestock and traditional agriculture (Vidaurre de la Riva et al., 2013), and large regions of the continent are included among the world's most important granaries (Manuel-Navarrete et al., 2009; Richardson, 2009). Consequently, drought is a first-order hydroclimatic hazard, with the potential for major impacts on the livelihoods of indigenous communities (Vidaurre de la Riva et al., 2013) and regional and national economies (CEPAL, 2012). In addition, recent studies have highlighted the environmental effects of droughts in South America, where even in very humid regions including the Amazon, severe droughts are triggering forest fires (Brando et al., 2014), reducing biomass production (Malhi et al., 2009; Brando et al., 2010) and causing widespread forest mortality (Phillips et al., 2009). In these regions the development of knowledge of how climate droughts vary in time and space, and of current trends in drought frequency, duration and severity is of great importance, given the implications of global warming scenarios. Other than a number of studies undertaken in the southern countries of Argentina (Scian and Donnari, 1997; Llano and Penalba, 2011; Scarpati and Capriolo, 2013) and Chile (Minetti et al., 2012), few studies have addressed these issues in South America. 
Bolivia is expected to be one of the countries most affected by continental reductions in water supplies as a consequence of climate change (Winters, 2012), and local communities consider drought to be the hydroclimatic hazard with most extensive impacts on agriculture in the region (Vidaurre de la Riva et al., 2013). Bolivia has high climatic and environmental diversity as a consequence of marked topographical gradients and diverse natural ecosystems. The north and east Amazonian regions are characterized by evergreen equatorial forests (Navarro and Ferreira, 2004), but the western Bolivian Altiplano (highlands) is dominated by dry tropical forests and large cultivated areas. Geographic and topographic diversity, and the influence of various atmospheric circulation mechanisms (Seiler et al., 2013) make the Bolivian climate highly complex (García et al., 2007; Escurra et al., 2014). Droughts are frequent, and the associated yield reductions lead to cumulative shortages of food for humans and animals (Jansen et al., 2000; Garcia et al., 2007). An indication of the importance of water availability in the region is that $50 \%$ of the active population of the Bolivian Altiplano is engaged in farming, with agricultural production of bitter potato and quinoa being major economic outputs, and export commodities. Over a large part of the Altiplano the rainfall during the agricultural season is less than half the atmospheric water demand (Vacher and Imaña, 1987), which reinforces negative impacts when a drought occurs. Vacher (1997) showed that drought causes large reductions in leaf water potential, green biomass, and production of the main crops of the region.

Moreover, recent studies have shown that Bolivian tropical dry forests are highly sensitive to droughts, with secondary growth and net primary production being markedly reduced as a response to long-lasting droughts (Mendivelso et al., 2014; Seiler et al., 2014). Toledo et al. (2011) showed that water availability is the main driver of forest growth in Bolivian tropical lowland forests, which range from evergreen Amazon forests to dry semi-deciduous Chiquitaño forests. Droughts also cause a decrease of vegetation activity in the Bolivian Altiplano (Washington-Allen et al., 1998). Furthermore, drought periods are associated with higher frequencies of forest fires in the tropical high Andes (Román-Cuesta et al., 2014), and impact on aquatic biological communities (Jansen et 
al., 2009). Their impact on water resources is also evident through effects on water supplies for the main cities, and the operational rules of the main reservoirs (Bender et al., 2002). Thus, restrictions on water supplies occurred in Bolivia during the wet seasons of 2008 and 2010 (Rangeroft et al., 2013).

In this study we analyzed the spatio-temporal variability and trends of droughts across Bolivia between 1955 and 2012, using two climate drought indices. The objectives of the study were: (i) to identify regions having a common temporal variability of droughts; (ii) to assess trends using different drought indices, considering precipitation droughts and also the influence of warming on drought severity; and (iii) to determine possible changes in drought duration and magnitude across the country.

\section{Data and methods}

\subsection{Dataset}

We used data series of monthly precipitation (P), and maximum (Tmax) and minimum (Tmin) temperature from 25 meteorological stations (hereafter, stations), recorded by the Bolivian Meteorological Service [Servicio Nacional de Meteorología e Hidrología (SENAMHI)]. The series comprised records of differing temporal length, and included data gaps. For this reason we retained series of precipitation from 21 stations that included records from 1955 to 2012 and had less than $10 \%$ data gaps. For 16 of these stations temperature series were also available, the majority starting in 1958. Therefore, our analysis was based on $21 \mathrm{P}$ series and $16 \mathrm{Tmax}$ and Tmin series. Figure 1 shows the location of the stations, and Table 1 lists their identity, coordinates and elevations.

The series were subject to quality control and homogenization. The quality control procedure was based on comparison of the rank of each data record with the average rank of the data recorded at adjacent stations (Vicente-Serrano et al., 2010). Inhomogeneities are common in climate data series because of changes in station location, alterations to the surrounding environment, observer changes and instrument replacement (Karl and Williams, 1987; Peterson et al., 1998). Relative homogeneity 
methods are commonly used to identify temporal homogeneity in climate series (Venema et al., 2012). For this purpose we used a recently developed relative homogeneity method (HOMER HOMogenization software in R-), which compares each candidate series with a number of available series (Mestre et al., 2013). HOMER is a semi-automatic methodology that combines a fully automatic joint segmentation with a partly subjective pairwise comparison. HOMER takes advantage of the results of the benchmarking process conducted in the framework of the European Community COST ACTION ES0601 (http://www.homogenisation.org/): "Advances in homogenization methods of climate series: an integrated approach (2007-2011)", and includes some of the techniques recommended after an inter-comparison study of homogenization procedures (Venema et al. 2012). Checking for inhomogeneities in each P, Tmax and Tmin series was based on analysis involving the 8 stations closest to each candidate station. The segmentation analysis was based on annual data, and used ratios for precipitation and temperature differences as a measure for comparisons. The method provides an estimation of break points in the time series relative to neighboring stations, and indicates high probabilities of the presence of inhomogeneities. Thus, if a break point was identified between a station and several of its neighboring stations for the same year, it was considered probable that there was inhomogeneity in the series. This approach was applied to each of the available P, Tmax and Tmin series. In the following procedure HOMER corrected the inhomogeneities and inserted missing values based on Equation 8 reported by Mestre et al. (2013). The procedure was iterated twice to eliminate possible inhomogeneities introduced when filling missing values.

Following the procedure of Jones and Hulme (1996), a single regional series for Bolivia was computed from the homogeneous series of $\mathrm{P}$, Tmax and Tmin, using the weighted averages of monthly records for each station. The weight factor was the ratio of the surface area represented by each station to the total area of Bolivia, based on Thiessen's polygon method.

\subsection{Drought Indices}


Objective data for quantifying drought (e.g. crop yields, streamflows, soil moisture) are commonly not available. For this reason the quantification of drought severity is typically carried out using drought indices, which are proxies based on climatic information; these indices are assumed to adequately quantify the degree of drought hazard for sensitive systems. The development of drought indices has recently been reviewed, and their advantages and drawbacks compared (Heim 2002; Keyantash and Dracup, 2002; Mishra and Singh, 2010; Sivakumar et al., 2010; Vicente-Serrano et al., 2011, 2012b, 2014). In this study we used two drought indices that are obtained from P and ETo series: the Standardized Precipitation Index (SPI) and the Standardized Precipitation Evapotranspiration Index (SPEI).

\section{a) The Standardized Precipitation Index (SPI)}

The SPI was proposed by McKee et al. (1993), and has been increasingly used during the two last decades because of its solid theoretical development, robustness, and versatility in drought analysis (Redmond, 2002). The SPI is based on the conversion of the precipitation data to probabilities, based on long-term precipitation records computed at various time scales. The probabilities are transformed to standardized series with an average of 0 and a standard deviation of 1 . The main advantage of the SPI is that it enables analysis of drought impacts at various temporal scales (Edwards and McKee, 1997), facilitating identification of different drought types. This is important as particular systems and regions can respond to drought conditions at very different time scales. We use the algorithm described by Vicente-Serrano (2006), based on the Pearson III distribution and the L-moments approach, to obtain the distribution parameters for calculating the 3-, 6-, 12- and 24-month SPI. On the shorter time scales (3 or 6 months), the dry and humid periods are short and occur with high frequency. At a time scale of 12 months droughts are less frequent but last longer. At longer time scales (24 or 36 months) droughts last longer but are less frequent, with few dry or humid periods recorded (Vicente-Serrano, 2006). Several studies have demonstrated variation in the 
response of agricultural (Quiring and Ganesh 2010) and ecological variables (Vicente-Serrano et al., 2006) to different time scales of the SPI.

\section{b) The Standardized Precipitation Evapotranspiration Index (SPEI)}

The main criticism of the SPI is that its calculation is based only on precipitation data. The SPI does not consider other variables that can influence drought severity, as it relies on two assumptions: (i) that the variability of precipitation is much greater than that of other variables, including temperature and reference evapotranspiration (ETo); and (ii) that the other variables are stationary (i.e., they have no temporal trend). The importance of variables other than precipitation is negligible in this framework, and droughts are assumed to be controlled mainly by the temporal variability of precipitation. Nevertheless, the effect of warming-induced drought stress has been made evident through several studies worldwide (e.g., Bresshears et al., 2005; Vicente-Serrano et al., 2014b). The SPEI (Vicente-Serrano et al., 2010b), which is based on P and ETo, introduced the sensitivity of drought severity to changes to the atmospheric evaporative demand in the multi-temporal nature based on a monthly climatic water balance ( $\mathrm{P}$ minus ETo), which is adjusted using a threeparameter log-logistic distribution. The values are accumulated at various time scales, following the same approach as is used for the SPI, and converted to standard deviations with respect to average values. The SPEI was also calculated at the 3-, 6-, 12- and 24-month time scales.

\subsection{Reference evapotranspiration (ETo) calculation}

To calculate SPEI it was necessary to determine the atmospheric evaporative demand, which is essential for interpreting drought as an imbalance between water availability and water demand. The atmospheric evaporative demand is heavily influenced by physical factors, and involves a combination of radiative and aerodynamic components (McVicar et al., 2012, and references therein). These components were combined by Penman (1948), who developed an equation to measure the evaporative demand of the atmosphere using meteorological data (wind speed, solar 
radiation, relative humidity and air temperature). Penman-based approaches provide accurate measures of atmospheric evaporative demand, consistent with measures based on pan evaporation (Roderick et al., 2009). Allen et al. (2008) used the Penman-Monteith approach to define the reference evapotranspiration (ETo), assuming a hypothetical crop with a height of $0.12 \mathrm{~m}$, a surface resistance of $70 \mathrm{~s} \mathrm{~m}^{-1}$, and an albedo of 0.23 (FAO-56 Penman-Monteith equation). The ETo value is only dependent on the meteorological conditions, and is comparable among regions independent of land conditions. Nevertheless, a common problem in estimating ETo is the absence of long time series of wind speed, solar radiation and relative humidity. This is the case for Bolivia. For this reason we used a simplified equation developed by Hargreaves and Samani (1985), which only requires information on maximum and minimum temperatures, and the extraterrestrial solar radiation. Based on this approach the ETo $\left(\mathrm{mm} \mathrm{day}^{-1}\right)$ was calculated using the equation:

ETo $=0.0023 \mathrm{R}_{\mathrm{a}} \mathrm{R}^{0.5}(\mathrm{~T}+17.8)$

where $\mathrm{R}$ is the difference between the maximum and minimum temperatures (monthly averages; ${ }^{\circ} \mathrm{C}$ ), $\mathrm{T}$ is the mean monthly temperature, and $\mathrm{Ra}$ is the extraterrestrial solar radiation expressed in equivalent evaporation $\left(\mathrm{mm} \mathrm{day}^{-1}\right)$, which depends on the latitude and the day of the year.

Various studies have shown that at monthly and annual time scales, ETo estimates based on this approach are very similar to those derived from the FAO-56 Penman-Monteith equation (differences $< \pm 2 \mathrm{~mm} \mathrm{day}^{-1}$; Droogers and Allen, 2002). Hargreaves and Allen (2003) showed that the relationship between the monthly ETo calculated using the Hargreaves and Samani method and that measured using a lysimeter varied from 0.97 to 1.01 for various semi-arid and sub-humid regions of the United States. Therefore, although this equation has some shortcomings in relation to more robust physical approaches, it was the most reliable alternative for estimating the long-term atmospheric evaporative demand in Bolivia.

\subsection{Identification of drought events}


To define drought events a threshold level that did not vary in time and space was applied to the 3month SPI and SPEI. We did not apply it to longer time scales, given the lower drought frequencies and number of events that occurred at the 3-month time scale. The threshold level was set at $20 \%$ (P20) of the cumulative probability (SPI or SPEI $<-0.84$, based on fitting to a normal standard distribution), and consequently a drought event was registered when the monthly 3-month SPI or SPEI fell below that level (Figure 2). Based on this threshold, each identified drought event was characterized by the drought duration and magnitude. The duration of a given drought event was defined as a consecutive and uninterrupted time period (one or more months) having an observed SPI or SPEI $<$ P20 at a specific meteorological station. The drought magnitude was the accumulated deficit volume (defined as the sum of the deficit volumes generated during an uninterrupted number of months) delimiting a drought event as accumulated deficits of the SPI or SPEI. Series of drought duration and magnitude were created for each meteorological station following this approach.

\subsection{Statistical analysis}

We analyzed the spatial variability of the SPI and SPEI across Bolivia using principal component analysis (PCA). We obtained a classification of homogeneous areas according to the general temporal and spatial patterns of monthly precipitation and evolution of the climatic water balance (P-ETo). A PCA attempts to synthesize most of the total variation of a large number of highly intercorrelated variables into a small number of new uncorrelated variables. The procedure has been widely applied in climatological studies (e.g., Richman, 1986; Jollife, 1986, 1990; Huth, 2006). The uncorrelated variables obtained are termed principal components (PCs), and consist of linear combinations of the original variables. The application of PCA to climatic series can be performed in S or T modes (Serrano et al., 1999). In this study the S mode applied was used to derive general temporal patterns. A correlation matrix was selected to efficiently represent the variance in the PCA dataset (Barry and Carleton, 2001). The number of components selected was based on the criterion of an eigenvalue $>1$, and the components were rotated (Varimax) to redistribute the final explained 
variance, and to obtain more stable, physically robust patterns (Richman, 1986). The areas represented by each mode (component) were identified by mapping the factorial loadings, which involved grouping the stations based on the maximum loading rule. Each station was assigned to the component with the highest loading value, and the P and ETo series corresponding to each PC extracted were also obtained using the weighted averages of the monthly records for each station, based on the Thiessen's polygon method (see above).

Trends in the seasonal (DJF, MAM, JJA, SON) 3-month and 12-month December (which is a summary of annual drought severity) SPI and SPEI series for particular stations, and trends in the series representative of different regions obtained through the PCA, were calculated using the Mann-Kendall tau rank correlation coefficient (Kendall, 1955). This statistic is more robust than parametric tests, and does not assume normality of data (Lanzante, 1996). The values of tau measure the degree to which a trend is consistently increasing or decreasing. Significant trends were defined as those with p-values $<0.05$. An important shortcoming of this method is that the nonparametric tau coefficient only showed the presence of significant trends in the series of the SPI and SPEI, but not the magnitude of change (in z-units). A small sustained change can result in a higher coefficient than a large abrupt change. To identify the magnitude of the rates of change in the SPI and SPEI we used a regression analysis between the series of time (independent variable) and the SPI or SPEI series (dependent variable). The results yielded one model for each, and took the form $y=m t+b$. The regression constant $(b)$ and the coefficient $(m)$ were calculated using a leastsquare fit, with the year $(\mathrm{t})$ as the independent variable. The slope of each model $(\mathrm{m})$ indicated the change in the SPI or SPEI (z-units of change per year). The same methodology was used to determine trends in the series of duration and magnitude for the identified drought events.

\section{Results}

\subsection{General evolution}


Figure 3 shows the evolution of the 3-, 6-, 12- and 24-month SPI and SPEI derived from the regional series of precipitation and climatic water balance (P-ETo) for Bolivia. Short time scales showed higher temporal frequency than long time scales. Nevertheless, independently of the drought time scale, the various time series showed a similar temporal behavior. The main drought episodes occurred in the 1960s, and from 1995 to 2012. In contrast, the period from 1970 to 1995 was dominated by humid conditions, evident in both the SPI and the SPEI. There were no marked differences in the SPI regional series obtained for the 21 meteorological stations using available precipitation data, and the series obtained for the 16 meteorological stations using P and ETo data. Therefore, the time series of the SPI could be compared with the regional evolution of the SPEI during the study period. In general, the SPEI showed a similar temporal pattern to that of the SPI, and also detected the main drought episodes in the decades of 1960, 1990 and 2000. Nevertheless, from 1995 and particularly from 2008 the SPEI indicated greater drought severity than the SPI in the average regional series; this was evident for the various drought time scales analyzed.

\subsection{Spatial and temporal variability}

The PCAs applied to the 21 monthly precipitation (1955-2012) and 16 monthly climatic water balance (P-Eto) series (1958-2012) showed greater spatial heterogeneity for P-ETo than for P. The PCA for the $\mathrm{P}$ series identified two components explaining most of the spatial variability in the monthly $\mathrm{P}$ across Bolivia (Figure 4). Nevertheless, for the series of $\mathrm{P}$ minus ETo, the various components represented a much lower proportion of the variance, which indicated greater spatial heterogeneity in the evolution of the climatic water balances. The spatial pattern of the components demonstrated the differing variabilities of P and P-ETo across the country (Figure 5). The two PCs obtained from the P series represented two clearly defined regions: PC1 represented the western stations, which correspond mostly to the Altiplano; PC2 represented stations located in low elevation areas of the east and north of the region (the Amazonian basin). The SPI-based drought for these two regions indicated major differences (Figure 6). In the high elevation plains the 
temporal variability of droughts was much higher than that observed for the Amazonian region. Thus, the evolution of the region represented by PC2 resembled the regional series because of the higher average precipitation in the Amazonian region relative to the Altiplano. Independently of the SPI time scale, the drought frequency was higher in the Altiplano than in the Amazonian basin. The succession of dry and humid periods in the Altiplano indicated that the drought duration tended to be less than in the Amazon region, although the drought intensity (minimum SPI values) may have been equivalent. In the Altiplano, intense drought episodes were also recorded in the 1950s and 1960s. However, whereas the most severe episodes occurred between 1960 and 1965 in the Amazonian region, in the Altiplano the most severe episodes occurred between 1965 and 1970. Moreover, whereas in the Amazonian basin the period 1970 to 1995 was predominantly humid, in the high plains the most severe drought episodes occurred during the study period. At the time scale of 12 months a short but severe drought occurred between 1983 and 1984, and a long duration drought period commenced in 1989 and continued until 1996. The years between 2003 and 2006 were also predominantly dry, although the drought magnitude was less than in the previous drought. Marked spatial variability in the SPEI is shown in Figure 7. Each of the five PCs identified (Figure 5) represented small areas. The westernmost stations of the Altiplano were highly correlated with PC1. The SPEI evolution in this region resembled the evolution of PC1 from the P series, with the main drought episodes being recorded in the periods 1965-1970, 1983-1984, 1990-2000 and 2003-2006. PC2 represented the northern stations of the Amazon region, and showed a similar temporal evolution to that of PC2 obtained from the P series. Nevertheless, the SPEI for this region showed that the drought period that commenced in 2000 was higher in magnitude and had greater temporal continuity than indicated by the SPI. We showed that these two general time series were representative of most of the country using the SPI. Nevertheless, including ETo as a driver of drought severity in the SPEI indicated that for the three southernmost stations (PC3), although drought conditions dominated in the periods 1965-1970 and 1983-1984, severe droughts also occurred in the periods 1975-1980, 1988-1992 and 2010-2012. Also noteworthy is that for the 
stations on the eastern slopes of the Altiplano (PC4) there was a general intensification of drought severity during the study period, with the most intense drought episodes occurring in the 1990s and 2000s. Additionally, a station in the eastern region, represented by PC5, showed a pattern characterized by higher frequency of dry and moist periods than was associated with PC2.

\subsection{Drought trends}

Analysis of the SPI and SPEI trends based on the PCA showed that at the annual scale (12-month) the magnitude of change in these indices between the 1950s and 2012 was low (Table 2). An exception was PC4 for the SPEI, for which there was a significant decrease $\left(0.21 \mathrm{z}\right.$-unit decade $\left.{ }^{-1}\right)$. No significant change in the magnitude of the SPI was found for either PC1 or PC2 in any season of the year, although during the winter period there was a dominant but non-significant decrease in the SPI. In contrast, there was a significant decrease in the SPEI in the regions represented by PC1, PC3 and PC4, which is indicative of an evolution toward more intense dry conditions between 1958 and 2012. In the period 1985-2012, in which more evident changes in drought severity are identified, there is a significant decrease of the annual 12-month SPI in the Amazon region (PC2) toward intensification of drought conditions. The drought intensification in both the Altiplano and the Amazon regions has been more important between June and November. Based on the SPEI, drought intensification from 1985 has been much more important, mainly in the Northeast of the country during all of the seasons and in the Altiplano (SPEI-PC2) from June to November.

The distribution of trends in the SPEI and SPI among the various stations enabled spatial differences to be identified (Figure 8). At the annual scale the SPI did not show a clear spatial pattern of change, although for some areas of the Altiplano and the eastern slopes the SPI predominantly decreased. A trend to greater drought severity was clearly evident in the SPEI, which indicated that drying dominated the Altiplano region, enhanced by evolution of the atmospheric water demand, which was included in the SPEI calculation. The trend of SPEI decrease in this region was mostly evident between June and August. Thus, the SPEI showed a different pattern to 
that of the SPI, both in the magnitude and spatial configuration of changes. At the annual scale the relative magnitudes of change in the SPI and the SPEI for each meteorological station analyzed were not significant (Figure 9). A significant difference in the magnitudes of change in the SPI and the SPEI was only recorded between December and May. From June to November the magnitudes of change in the SPI and the SPEI were not related. These results indicate that the patterns of drought variability and change between December and May were mainly driven by precipitation, but between June and November the atmospheric evaporative demand also played a substantial role. Thus, in the winter period the ETo appeared to be more important than $\mathrm{P}$ in explaining drought trends, probably as a consequence of the seasonal precipitation regime characterised by low precipitation in winter months in comparison to the summer.

Some spatial patterns were evident in trends in the duration and magnitude of drought events (Figure 10); the spatial patterns were similar (Figure 11), as the duration and magnitude of each drought event were closely related (for each event, a longer duration was usually associated with a higher drought magnitude). An increase in the duration and magnitude of drought events was indicated by data from stations located in the Altiplano, particularly with respect to the SPEI. The average duration of droughts recorded at some of these stations increased by more than 0.3 months decade $^{-1}$, which suggests that average drought duration in this area had increased by more than 1.5 months since 1958. In contrast, the records for some stations in the south of Bolivia indicate that there had been a decrease in the drought duration and magnitude. The spatial patterns of change in drought duration and magnitude measured by both the SPI and the SPEI were not related (Figure 12A). This supports the hypothesis that including ETo in drought quantification affects the drought index values but also the assessment of drought events in terms of duration and magnitude. The SPEI indicated longer drought duration than the SPI, although in general the spatial patterns appeared random.

Figure 12B shows the relationship between the changes in annual SPI and SPEI (12-months, December) and the observed changes in drought duration and magnitude. This analysis is relevant 
because a decrease in either index does not necessarily mean that higher magnitudes or longer durations of drought will be recorded. How the drought index values are grouped temporally will also determine the final assessment of drought severity. If greater drought duration or magnitude accompanies more negative SPI or SPEI values, the severity of the drought episodes could increase markedly. This reflects what we observed for the SPI and SPEI trends. Those stations for which more negative SPEI and SPI trends were found were associated with the occurrence of increased duration and magnitude of drought episodes. Both patterns were typically recorded at stations located in the Altiplano, particularly with respect to the SPEI, highlighting that in this region drought severity shows the main increase associated with ETo trends, drought episodes.

\section{Discussion and conclusions}

In this study we analyzed drought variability and trends in Bolivia from 1955 to 2012. This is the first long-term assessment of the spatio-temporal drought variability in Bolivia using two climatic drought indices: the Standardized Precipitation Index (SPI) and the Standardized Precipitation Evapotranspiration Index (SPEI). We demonstrated that average drought conditions across the country were characterized by decadal variations. Nevertheless, the spatial patterns of drought differed markedly between the Amazonian and the Bolivian Altiplano regions. These regions showed very different evolution of the SPI, and the main droughts occurred in different periods. Thus, the average pattern for the country was primarily driven by events in the Amazonian region, where precipitation levels are much higher than in the Altiplano. We also showed that inclusion of reference evapotranspiration (ETo), obtained from maximum and minimum temperature records, increased the spatial heterogeneity of drought evolution in relation to that observed when only precipitation droughts were considered. Although temperature is usually more spatially homogeneous than precipitation, the complex topographical and environmental diversity in Bolivia could account for the high regional heterogeneity. In this regard, Seiler et al. (2013) showed that recent trends in the spatial patterns of temperature in Bolivia are complex, both between the 
Amazonian and the Altiplano regions, but also between the southern and northern parts of the Altiplano; this is consistent with the different patterns of SPEI variability found for these regions.

We showed that droughts occurred with higher frequency in the Bolivian Altiplano than in the Amazonian region. This can be explained by the different atmospheric circulation mechanisms that control the climate in Bolivia. The drought pattern observed for the Amazonian region resembles the pattern of annual precipitation reported by Seiler et al. (2013), who associated the lowfrequency variability with the evolution of the Pacific Decadal Oscillation (PDO). In contrast, various studies have related climate variability in the Altiplano to the El Niño Southern Oscillation (ENSO), with droughts being primarily driven by El Niño phases (Thompson et al., 1984; Francou, 1985; Tapley and Waylen, 1990; Garreud and Aceituno, 2001). Espinoza-Vilar (2009) reported a general decrease in precipitation throughout the entire South American Amazonian region since the 1980s, which is consistent with the SPI observations. They stressed that most variability in the Amazonian basin is associated with long-term changes in the Pacific Ocean, which determines changes in the strength of the low-level jet along the Andes. In contrast, in the southern tropical Andes, where the Bolivian Altiplano is located, the ENSO plays a more significant role. Vizy and Cook (2007) found that rainfall over the Peruvian and Bolivian Andes can increase despite largescale drying over South America, highlighting that the Amazon basin is the moisture source for the Andes, but that rainfall variability over the central Andes is not directly controlled by moisture changes in the Amazon basin. These physical mechanisms could explain the different drought behaviors found between these two Bolivian regions.

We also showed that there were small differences between the evolution of the SPI and the SPEI across Bolivia. Both indices recorded similar temporal patterns, with the most intense drought episodes having occurred in the 1960s and 2000s. Nevertheless, the SPEI (the calculation of which includes $\mathrm{P}$ and ETo) indicated some intensification in drought severity in recent years relative to the pattern found when precipitation droughts alone were considered. This is evident when drought trends have been analyzed for the period 1985-2012. This pattern may be related to the general 
increase in temperature that has occurred in the Andes (Vuille and Bradley, 2000; Bradley et al., 2006), which is estimated to have been $0.1^{\circ} \mathrm{C}$ decade ${ }^{-1}$ since 1940 (Vuille et al., 2008); this is consistent with the increase reported for Bolivia by Seiler et al. (2013) for the period 1960-2009. Thus, we found greater differences between trends in the SPEI and the SPI for those areas of Bolivia (the Altiplano) in which Vuille et al. (2003) showed a greater temperature increase.

Various studies have suggested that global warming may increase drought severity as a consequence of increased atmospheric evaporative demand (e.g., Dai, 2013; Vicente-Serrano et al., 2014). The results obtained for Bolivia also suggest this pattern, as inclusion of reference evapotranspiration reinforced drought severity in the SPEI calculations relative to the SPI. Nevertheless, these results need to be treated with caution as a number of studies have demonstrated that the atmospheric evaporative demand is a function of both temperature (Penman, 1948) and a combination of aerodynamic and radiative components (McVicar et al., 2012). These are a function of air temperature, but also relative humidity, wind speed and solar radiation. Thus, given the evolution of these variables, the atmospheric evaporative demand could decrease as a consequence of reduced radiative forcing (Roderick and Farquar, 2002) and/or a decrease in wind speed (McVicar et al., 2012b). At present there are no long time series of these variables available for Bolivia, and consequently no definitive conclusion can be made that drought severity in Bolivia is increasing as a consequence of greater atmospheric evaporative demand.

Nevertheless, there are indirect indicators for this hypothesis. Reference evapotranspiration is much greater than precipitation in the Bolivian Altiplano (García et al., 2004), and its importance in determining drought severity should not be neglected. The length of the growth period for quinoa and potato (the main crops cultivated in the Altiplano) is longer than the rainy season, and the mean precipitation is less than the water requirements for these crops: approximately $500 \mathrm{~mm}$ for quinoa and $700 \mathrm{~mm}$ for potatoes (Vacher et al., 1988). Therefore, the combined effects of variability in precipitation and reference evapotranspiration must be considered in explaining the marked yearly variation in crop production (García et al., 2007). In addition, Escura et al. (2014) used the soil and 
water assessment tool (SWAT) to analyze the impact of precipitation and temperature on the water budget for Bolivia, and showed a trend of decreased runoff as a consequence of decreased precipitation, and a negative influence of increased temperature. Fry et al. (2012) modeled streamflows in the Alto Benia region of the Altiplano, where the community has expressed concern over a perceived decline in discharge from natural springs. This reduction is believed to be because of reduced infiltration and recharge as a consequence of agricultural expansion. Nevertheless, Fry et al. (2012) showed that hydrological modeling predicted a net decrease in average recharge by climate variability, hydrological droughts may be a consequence of climate change processes rather than land use changes. Thus, a local view is that there has been an increase in the frequency of drought events, and that this is the principal reason for agricultural losses (Vidaurre de la Riva et al., 2013). It is expected that farmers experience reaches only 20-30 years back, but as we have showed for the 1985-2012 period, there is strong increase in drought severity in the Altiplano, mainly as a consequence of the evolution of ETo. This is in agreement with the fact that farmers on the Altiplano have reported that the frequency and intensity of extreme events is higher than in previous years, and have indicated that during the dry season the droughts last longer (Vidaurre de la Riva et al., 2013). This could be consistent with increased atmospheric evaporative demand in the Altiplano; whereas the SPI did not show a clear pattern of change consistent with decreased runoff and crop yields, the SPEI showed a clear decrease. In addition, the duration and magnitude of drought events based on the SPEI is clear for the Altiplano. As the difference between the SPI and the SPEI is related to inclusion of the ETo in the calculation of the latter, it is reasonable to assume that an increase in this variable will increase drought severity.

The consequences of climate change may exacerbate droughts in this region. Various studies have used general circulation models (GCMs) to determine possible future climate evolution in the region. These studies show an evolution toward a drier and warmer climate during the dry season. Marengo et al. (2011) showed that GCMs predict substantial warming (4-6 ${ }^{\circ} \mathrm{C}$ ) by the end of the 21 st century in continental South America, and larger increases in coastal regions. This may lead to 
steep sea level pressure gradients between the continent and the oceans, and changes in moisture transport and rainfall, with reductions occurring in the Amazonia region. Studies focused on Bolivia have predicted reductions in summer soil moisture from approximately 2020 onward, resulting from reductions in summer rainfall and higher evapotranspiration rates (Thibeault et al., 2012). Seth et al. (2010) and Thibeault et al. (2012) used the GCMs of the coupled model intercomparison project (CMIP3) to show that in the Bolivian Altiplano the observed warming is likely to accelerate in coming decades, because of changes in atmospheric circulation. Seiler et al. (2013b) recently used 35 global circulation models under five emission scenarios for the period 2070-2099 to project an increase in temperature in Bolivia from 2.5 to $5.9^{\circ} \mathrm{C}$, and to predict a decrease in precipitation of $9 \%$, with the main decline in precipitation (a decrease of 19\%) expected during the driest months. although at the annual scale different ENSEMBLES show more uncertainties (Chadwick et al., 2013). Thibeault et al. (2010) also showed a substantial increase in the occurrence of heat waves in the Altiplano, which are expected to increase the atmospheric evaporative demand and decrease vegetation productivity during dry months. Under these conditions, the survival of current agricultural and ecological systems may be seriously threatened, necessitating the development in coming decades of adaptive measures to cope with drought changes in Bolivia.

An essential task for the future drought mitigation may be the development of drought plans (Wilhite, 1996), in which a critical component is the provision of timely and reliable climatic information to be the base of management decisions (Iglesias et al., 2007). For this reason, the synthetic drought indicators used in this study may inform about the spatial extent and severity of drought conditions to express the level of risk in a way which is easy to understand by the endusers. There are different drought monitoring systems that are using the SPI (e.g., http://www.dmcsee.org/) or the SPEI (http://sac.csic.es/spei/map/maps.html). Implementation of these indices in an operational drought monitoring system in Bolivia would be a step further toward drought mitigation in the region. 


\section{Acknowledgements}

This work has been supported by research projects I-COOP $\mathrm{H}_{2} \mathrm{O}$ 2013CD0006: "Test multisectorial y actividades demostrativa sobre el potencial desarrollo de sistemas de monitorización de sequías en tiempo real en la región del oeste de Sudamérica" financed by the Spanish National Research Council (CSIC), CGL2011-27574-CO2-02 financed by the Spanish Commission of Science and Technology and FEDER, "Demonstration and validation of innovative methodology for regional climate change adaptation in the Mediterranean area (LIFE MEDACC)" financed by the LIFE programme of the European Commission,. C. A-M received a postdoctoral fellowship\# JCI-201110263. A. S-L is supported by the "Secretaria per a Universitats i Recerca del Departament d'Economia i Coneixement, de la Generalitat de Catalunya i del programa Cofund de les Accions Marie Curie del 7è Programa marc d'R+D de la Unió Europea" (2011 BP-B 00078) and the postdoctoral fellowship \# JCI-2012-12508.

\section{References.}

Allen, R.G.; L. S. Pereira, D. Raes and M. Smith (1998). - Crop evapotranspiration - Guidelines for computing crop water requirements - FAO Irrigation and drainage paper 56.

Barry, R. G., and A. M. Carleton (2001), Synoptic and Dynamic Climatology, Routledge, London. Bender, M.J., Hranisavljevic, D., Bernardin, R. and Bianchi, R., (2002): Dynamic operating rules for water supply reservoirs in La Paz. Water Science and Technology, 46: 247-254.

Bradley, R. S., M. Vuille, H. F. Diaz, and W. Vergara (2006), Threats to water supplies in the Andes, Science, 312, 1755 -1756, doi:10.1126/ science.1128087.

Brando, P.M., (2010): Seasonal and interannual variability of climate and vegetation indices across the Amazon Proceedings of the National Academy of Sciences of the United States of America 107: 14685-14690.

Brando, P.M., et al., (2014): Abrupt increases in Amazonian tree mortality due to drought-fire interactions. Proceedings of the National Academy of Sciences of the United States of America 111: 6347 - 6352.

Breshears DD, et al. (2005) Regional vegetation die-off in response to global-change type drought. Proc Natl Acad Sci USA 102(42):15144-15148.

CEPAL, Comisión Económica para América Latina y el Caribe (2012): Estudio económico de $\begin{array}{llllll}\text { América Latina } & y & \text { el } & \text { Caribe } & \text { - } & \text { 2010-2011 }\end{array}$ http://www.cepal.org/publicaciones/xml/1/43991/EEE-Argentina.pdf

Dai A 2013 Increasing drought under global warming in observations and models Nature Clim. Change $352-8$

Droogers P, Allen RG. 2002. Estimating reference evapotranspiration under inaccurate data conditions. Irrigation and Drainage Systems 16: 33-45.

Edwards, D. C., and T. B. McKee, 1997: Characteristics of 20th century drought in the United States at multiple time scales. Colorado State University Department of Atmospheric Science Climo Rep. 97-2, 155 pp. 
Escurra, J.J., Vazquez, V., Cestti, R., De Nys, E., Srinivasan, R., (2014): Climate change impact on countrywide water balance in Bolivia. Reg Environ Change 14:727-742

Espinoza Villar, J.C., et al., (2009): Spatio-temporal rainfall variability in the Amazon basin countries (Brazil, Peru, Bolivia, Colombia, and Ecuador). International Journal of Climatology, 29: 1574-1594.

Francou, B., (1985): 'El Nino' and the drought in the High Central Andes of Peru and Bolivia. Bulletin - Institut Francais des Etudes Andines 14: 1-18.

Fry, L.M., Watkins, D.W., Reents, N., Rowe, M.D., and Mihelcic, J.R., (2012): Climate change and development impacts on the sustainability of spring-fed water supply systems in the Alto Beni region of Bolivia. Journal of Hydrology 468-469: 120-129.

Garcia, M., Raes, D., Allen, R. and Herbas, C., (2004): Dynamics of reference evapotranspiration in the Bolivian highlands (Altiplano). Agricultural and Forest Meteorology 125: 67-82.

Garcia, M., Raesb, D., Jacobsenc, S.-E. and Micheld, T. (2007): Agroclimatic constraints for rainfed agriculture in the Bolivian Altiplano. Journal of Arid Environments 71: 109-121.

Garreaud, R. and Aceituno, P., (2001): Interannual rainfall variability over the South American Altiplano. Journal of Climate 14(12): 2779-2789.

Guillermo, H. (2010): L'économie argentine et l'agriculture d'exportation, 2002-2009: Enjeux et conflits. Agroalimentaria 16: 15-45.

Hargreaves GL, Allen RG. 2003. History and evaluation of Hargreaves evapotranspiration equation. Journal of Irrigation and Drainage Engineering-ASCE 129: 53-63.

Hargreaves GL, Samani ZA. 1985. Reference crop evapotranspiration from temperature. Applied Engineering in Agriculture 1: 96-99.

Heim, R. R., 2002: A review of twentieth-century drought indices used in the United States. Bull. Amer. Meteor. Soc., 83, 1149-1165.

Hunt, E.D., et al., (2014): Monitoring the effects of rapid onset of drought on non-irrigated maize with agronomic data and climate-based drought indices. Agricultural and Forest Meteorology 191: 1-11.

Huth, R. (2006), The effect of various methodological options on the detection of leading modes of sea level pressure variability, Tellus, Ser. A, 58, 121-130.

Iglesias, A., Garrote, L., Flores, F. and Moneo, M., (2007): Challenges to manage the risk of water scarcity and climate change in the Mediterranean. Water Resources Management, 21: 775788.

Jansen, M., Schulze, A., Werding, L. and Streit, B. (2009): Effects of extreme drought in the dry season on an anuran community in the Bolivian Chiquitano region. Salamandra, 45: 233238.

Jollife, I. T. (1986), Principal Component Analysis, 271 pp., Springer, New York.

Jollife, I. T. (1990), Principal component analysis: A beginner's guide. Part I: Introduction and application, Weather, 45, 375-382.

Jones, P.D. and Hulme, M., (1996): Calculating regional climatic time series for temperature and precipitation: methods and illustrations. International Journal of Climatology. 16: 361-377.

Karl TR, Williams CN. 1987. An approach to adjusting climatological time series for discontinuous inhomogeneities. Journal of Climate and Applied Meteorology 26: 1744-1763.

Kendall, M.G. (1955). Rank Correlation Methods. Griffin, London..

Keyantash, J., and J. Dracup, 2002: The quantification of drought: An evaluation of drought indices. Bull. Amer. Meteor. Soc., 83, 1167-1180.

Lanzante J.R., (1996): Resistant, robust and non-parametric techniques for the analysis of climate data: theory and examples, including applications to historical radiosonde station data. International Journal of Climatology 16: 1197-1226.

Llano, M.P., and Penalba, O.C., (2011): A climatic analysis of dry sequences in Argentina. International Journal of Climatology 31: 504-513. 
Malhi, Y. et al., (2009): Exploring the likelihood and mechanism of a climate-change-induced dieback of the Amazon rainforest. Proceedings of the National Academy of Sciences of the United States of America 106: 20610-20615.

Manuel-Navarrete, D. et al., (2009): Multi-causal and integrated assessment of sustainability: The case of agriculturization in the Argentine Pampas. Development and Sustainability 11: 621638.

McVicar, T.R., Roderick, M.L., Donohue, R.J., Van Niel, T.G., (2012): Less bluster ahead?. Ecohydrological implications of global trends of terrestrial near-surface wind speeds. Ecohydrology, 5: 381-388.

McVicar, T.R., Michael L. Roderick, Randall J. Donohue, Ling Tao Li, Thomas G. Van Niel, Axel Thomas, Jürgen Grieser, Deepak Jhajharia, Youcef Himri, Natalie M. Mahowald, Anna V. Mescherskaya, Andries C. Kruger, Shafiqur Rehman, Yagob Dinpashoh (2012): Global review and synthesis of trends in observed terrestrial near-surface wind speeds: Implications for evaporation. Journal of Hydrology 416-417: 182-205.

Minetti, J. L. et al., (2010): Regional droughts in southern South America. Theor Appl Climatol 102: 403-415.

Mishra, A. K., and V. P. Singh, 2010: A review of drought concepts. J. Hydrol., 391, 202-216.

Marengo; J.A., (2012): Development of regional future climate change scenarios in South America using the Eta CPTEC/HadCM3 climate change projections: climatology and regional analyses for the Amazon, Sao Francisco and the Paraná River basins. Clim Dyn, 38:1829 1848.

McKee, T. B. N., J. Doesken, and J. Kleist, 1993: The relationship of drought frequency and duration to time scales. Proc. Eight Conf. on Applied Climatology. Anaheim, CA, Amer. Meteor. Soc. 179-184.

Mendivelso, H.A., Camarero, J.J., Gutiérrez, E. and Zuidema, P.A. (2014): Time-dependent effects of climate and drought on tree growth in a Neotropical dry forest: Short-term tolerance vs. long-term sensitivity. Agricultural and Forest Meteorology, 188: 13-23.

Mestre, O., Domonkos, P., Picard, F., Auer, I., Robin, S., Lebarbier, E., Böm, R., Aguilar, E... (2013): HOMER: a homogenization software - methods and applications. IDOJÁRÁS. Quarterly Journal of the Hungarian Meteorological Service, 117: 47-67.

Morales, A., Olcina, J. and Rico, A.M., (2000): Diferentes persepciones de la sequía en España: adaptación, catastrofismo e intentos de corrección. Investigaciones Geográficas, 23: 5-46.

Navarro, G. and Fereira, W., (20049: Zonas de vegetación potencial de Bolivia: una base para el análisis de vacíos de conservación. Rev. Bol. Ecol. 15: 40 pag.

Nicholson, S.E., Tucker, C.J. and Ba, M.B., (1998): Desertification, drought and surface vegetation: an example from the west African Sahel. Bulletin of the American Meteorological Society. 79: 815-829.

Penman, H.L. (1948). Natural evaporation from open water, bare soil, and grass. Proc. Roy. Soc. London A193:120-146.

Peterson ThC, Easterling DR, Karl ThR, Groisman P, Nicholls N, Plummer N, Torok S, Auer I, Boehm R, Gullett D, Vincent L, Heino R, Tuomenvirta H, Mestre O, Szentimrey T, Salinger J, Førland EJ, Hanssen-Bauer I, Alexandersson H, Jones Ph, Parker D. 1998. Homogeneity adjustments of in situ atmospheric climate data: a review. International Journal of Climatology 18: 1493-1517.

Phillips, O.L. et al., (2009): Drought sensitivity of the amazon rainforest. Science 323: 1344-1347.

Potop, V., Možný, M. and Soukup, J. (2012): Drought evolution at various time scales in the lowland regions and their impact on vegetable crops in the Czech Republic. Agricultural and Forest Meteorology, 156: 121-133.

Quiring, S.M., and S. Ganesh, 2010: Evaluating the utility of the vegetation condition index (VCI) for monitoring meteorological drought in Texas. Agric. For. Meteor., 150, 330-339. 
Rangecroft, S., Stephan Harrison, Karen Anderson, John Magrath, Ana Paola Castel, Paula Pacheco (2013): Climate Change and Water Resources in Arid Mountains: An Example from the Bolivian Andes. Ambio, 42:852-863.

Redmond, K. T., 2002: The depiction of drought. Bull. Amer. Meteor. Soc., 83, 1143-1147.

Richardson, N.P. (2009): Export-oriented populism: Commodities and coalitions in Argentina. Studies in Comparative International Development 44: 228-255.

Richman, M. B. (1986), Rotation of principal components, J. Climatol., 6, 293- 335

Roderick, M.L., Farquhar, G.D., 2004. Changes in Australian pan evaporation from 1970 to 2002. Int. J. Climatol. 24 (9), 1077-1090.

Roderick, M.L., Michael T. Hobbins and Graham D. Farquhar (2009): Pan Evaporation Trends and the Terrestrial Water Balance. I. Principles and Observations. Geography Compass 3: 746760.

Román-Cuesta, R.M., et al., (2014): Synchronous fire activity in the tropical high Andes: An indication of regional climate forcing. Global Change Biology. In press.

Scarpati, O.E., Capriolo, A.D. (2013): Sequías e inundaciones en la provincia de Buenos Aires (Argentina) y su distribución espacio-temporal. Investigaciones Geográficas 82: 38-51.

Scian, B. and Donnari, M., (1997). Retrospective analysis of the palmer drought severity index in the semi-arid pampas region, Argentina. International Journal of Climatology, 17, 313-322.

Seiler, C., Hutjes, R.W.A., Kabat, P. (2013): Climate variability and trends in Bolivia. Journal of Applied Meteorology and Climatology 52: 130-146.

Seiler, C., Hutjes, R.W.A., Kabat, P. (2013b) Likely ranges of climate change in Bolivia. Journal of Applied Meteorology and Climatology 52: 1303-1317.

Seiler, C., R. W. A. Hutjes, B. Kruijt, J. Quispe, S. Añez, V. K. Arora, J. R. Melton, T. Hickler, and P. Kabat (2014), Modeling forest dynamics along climate gradients in Bolivia, J. Geophys. Res. Biogeosci., 119, 758-775

Serrano, A., J. Garciacute;a, V. Mateos, M. L. Cancillo, and J. Garrido (1999), Monthly modes of variation of precipitation over the Iberian Peninsula, J. Clim., 12, 2894-2919,

Seth, A., Jeanne Thibeault, Magali Garcia \& Corinne Valdivia (2010) Making Sense of TwentyFirst-Century Climate Change in the Altiplano: Observed Trends and CMIP3 Projections, Annals of the Association of American Geographers, 100:4, 835-847,

Sivakumar,M. V. K., R. P. Motha, D. A.Wilhite, and D. A.Wood, Eds., 2010: Agricultural Drought Indices: Proceedings of an Expert Meeting. 2World Meteorological Organization, $219 \mathrm{pp}$.

Tapley, T.D. Jr and Waylen, P.R., (1990): Spatial variability of annual precipitation and ENSO events in western Peru. Hydrological Sciences 35:429-446.

Thibeault, J. M., A. Seth, and M. Garcia (2010), Changing climate in the Bolivian Altiplano: CMIP3 projections for temperature and precipitation extremes, J. Geophys. Res., 115, D08103, doi:10.1029/2009JD012718.

Thibeault, J., Anji Seth and Guiling Wang, (2012): Mechanisms of summertime precipitation variability in the Bolivian Altiplano: present and future. Int. J. Climatol. 32: 2033-2041.

Thompson, L.G., Mosley-Thompson, E. and Arnao, B.M., (1984): El Niño-Southern Oscillation events recorded in the stratigraphy of the tropical Quelccaya ice cap, Peru. Science 226:50 53.

Toledo, M., (2011): Climate is a stronger driver of tree and forest growth rates than soil and disturbance. Journal of Ecology, 99: 254-264.

Vacher, J.J., Imaña, E., (1987): Los riesgos climaticos en el altiplano Boliviano. OMM-SENAMHIORSTOM, La Paz, Bolivia, 30 pp.

Vacher, J.J. (1998): Responses of two main Andean crops, quinoa, Chenopodium quinoa Will and papa amarga Solanum juzepczukii Buk. to drought on the Bolivian Altiplano: Significance of local adaptation. Agriculture, Ecosystems and Environment 68: 99-108.

Venema, V.K.C., Mestre, O., Aguilar, E., Auer, I., Guijarro, J.A., Domonkos, P., Vertacnik, G., (...), Brandsma, T. 2012 Benchmarking homogenization algorithms for monthly data. Climate of the Past 8 (1) , pp. 89-115 
Vergara, W., (2009): Assessing the potential consequences of climate destabilization in Latin America. Latin America and Caribbean region Sustainable Development Working Paper 32. The World Bank, Latin America and the Caribbean Region Sustainable Development Department.

Vicente-Serrano, S. M., 2006: Differences in spatial patterns of drought on different time scales: An analysis of the Iberian Peninsula. Water Resour. Manage., 20, 37-60.

Vicente-Serrano, S.M., Beguería, S., Juan I. López-Moreno, Miguel A. García-Vera y P. Stepanek. (2010): A complete daily precipitation database for North-East Spain: reconstruction, quality control and homogeneity. International Journal of Climatology. 30, 1146-1163.

Vicente-Serrano S.M., Santiago Beguería, Juan I. López-Moreno, (2010b) A Multi-scalar drought index sensitive to global warming: The Standardized Precipitation Evapotranspiration Index - SPEI. Journal of Climate 23: 1696-1718.

Vicente-Serrano, S.M., Beguería, S. and Juan I. López-Moreno (2011). Comment on "Characteristics and trends in various forms of the Palmer Drought Severity Index (PDSI) during 1900-2008" by A. Dai. Journal of Geophysical Research-Atmosphere. 116, D19112, doi:10.1029/2011JD016410.

Vicente-Serrano, S.M., Aidel Zouber, Teodoro Lasanta, and Yolanda Pueyo. (2012); Dryness is accelerating degradation of vulnerable shrublands in semiarid Mediterranean environments. Ecological Monographs, 82, 407-428.

Vicente-Serrano, S.M., Santiago Beguería, Jorge Lorenzo-Lacruz, Jesús Julio Camarero, Juan I. López-Moreno, Cesar Azorin-Molina, Jesús Revuelto, Enrique Morán-Tejeda and Arturo Sánchez-Lorenzo. (2012b) Performance of drought indices for ecological, agricultural and hydrological applications. Earth Interactions 16, 1-27.

Vicente-Serrano, S.M., Gerard Van der Schrier, Santiago Beguería, Cesar Azorin-Molina, Juan-I. Lopez-Moreno. (2014): Contribution of precipitation and reference evapotranspiration to drought indices under different climates. Journal of Hydrology.

Vicente-Serrano, S.M., Juan-I. Lopez-Moreno, Santiago Beguería, Jorge Lorenzo-Lacruz, Arturo Sanchez-Lorenzo, José M. García-Ruiz, Cesar Azorin-Molina, Jesús Revuelto, Ricardo Trigo, Fatima Coelho, Francisco Espejo.(2014b) Evidence of increasing drought severity caused by temperature rise in southern Europe. Environmental Research Letters. 9, 044001. doi:10.1088/1748-9326/9/4/044001

Vidaurre de la Riva, M., Lindner, A., Pretzsch, J., (2013): Assessing adaptation - Climate change and indigenous livelihood in the Andes of Bolivia. Journal of Agriculture and Rural Development in the Tropics and Subtropics 114: 109-122.

Vizy, E. K., and K. H. Cook (2007), Relationship between Amazon and high Andes rainfall, J. Geophys. Res., 112, D07107, doi:10.1029/2006JD007980.

Vuille, M. and Bradley, R.S., (2000): Temperature trends and their vertical structure in the tropical Andes. Geophysical Research Letters 27:3885-3888.

Vuille, M., Francou, B., Wagnon, P., Juen, I., Kaser, G., Mark, B.G. and Bradley, R.S., (2008): Climate change and tropical Andean glaciers: Past, present and future. Earth-Science Reviews 89: 79-96.

Washington-Allen, R.A., Ramsey, R.D., Norton, B.E. and West, N.E. (1998): Change detection of the effect of severe drought on subsistence agropastoral communities on the Bolivian Altiplano. International Journal of Remote Sensing 19: 1319-1333.

Wilhite, D.A., (1996): A methodology for drought preparedness. Natural Hazards, 13: 229-252.

Winters, C. (2012): Impact of climate change on the poor in Bolivia. Global Majority E-Journal 3: $33-43$. 
Table 1. The meteorological stations involved in the study. The last column indicates the data available from each station (2: precipitation and temperature, 1: only precipitation). Coordinates: degrees and 1/100ths of degrees. Elevation: $m$ a.s.l.

\begin{tabular}{|l|r|r|r|r|}
\hline Observatory & Latitude & Longitude & Elevation & Variables \\
\hline Trompillo Aeropuerto & -17.81 & -63.18 & 4132 & 1 \\
\hline Trinidad Aeropuerto & -14.82 & -64.92 & 156 & 2 \\
\hline Tarija Aeropuerto & -21.55 & -64.71 & 1875 & 2 \\
\hline Sucre Aeropuerto & -19.01 & -65.29 & 2904 & 2 \\
\hline San Javier & -16.27 & -62.47 & 234 & 1 \\
\hline Rurrenabaque & & & & \\
Aeropuerto & -14.43 & -67.50 & 204 & 2 \\
\hline Robore & -18.33 & -59.76 & 277 & 1 \\
\hline Riberalta & -11.01 & -66.08 & 141 & 2 \\
\hline Patacamaya & -17.24 & -67.92 & 3793 & 1 \\
\hline Oruro Aeropuerto & -17.95 & -67.08 & 3702 & 2 \\
\hline Magdalena & -13.26 & -64.06 & 141 & 2 \\
\hline Potosi Los Pinos & -19.58 & -65.75 & 3950 & 2 \\
\hline Laykacota & -16.50 & -68.12 & 3632 & 2 \\
\hline El Alto Aeropuerto & -16.51 & -68.20 & 4071 & 2 \\
\hline Cobija Aeropuerto & -11.04 & -68.78 & 235 & 1 \\
\hline Cochabamba Aeropuerto & -17.42 & -66.17 & 2548 & 2 \\
\hline Camiri Aeropuerto & -20.01 & -63.53 & 810 & 2 \\
\hline Arani & -17.57 & -65.75 & 2767 & 2 \\
\hline Belen & -16.02 & -68.70 & 3833 & 2 \\
\hline Yacuiba & -21.97 & -63.65 & 580 & 2 \\
\hline Calacoto & -17.28 & -68.64 & 3826 & 1 \\
\hline
\end{tabular}


Table 2: Magnitude of change in the annual (12-month) and seasonal (3-month) SPI and SPEI series corresponding to the two PCs obtained from precipitation series, and the five PCs obtained from the series of climatic balances. The magnitude of change is provided in $\mathrm{z}$-units decade ${ }^{-1}$. indicates $^{-}$ statistically significant changes $(\mathrm{p}<0.05)$ based on the Mann-Kendall test. The trend analysis for the period 1985-2012 is also shown.

\begin{tabular}{|c|c|c|c|c|c|c|c|c|c|c|}
\hline & \multicolumn{5}{|c|}{ Complete series } & \multicolumn{5}{|l|}{$1985-2012$} \\
\hline & 12-month & $\begin{array}{l}\text { 3-month } \\
\text { DJF }\end{array}$ & $\begin{array}{l}\text { 3-month } \\
\text { MAM }\end{array}$ & $\begin{array}{l}\text { 3-month } \\
\text { JJA }\end{array}$ & $\begin{array}{l}\text { 3-month } \\
\text { SON }\end{array}$ & 12-month & $\begin{array}{l}\text { 3-month } \\
\text { DJF }\end{array}$ & $\begin{array}{l}\text { 3-month } \\
\text { MAM }\end{array}$ & $\begin{array}{l}\text { 3-month } \\
\text { JJA }\end{array}$ & $\begin{array}{l}\text { 3-month } \\
\text { SON }\end{array}$ \\
\hline \multicolumn{11}{|l|}{ SPI } \\
\hline PC1 & 0.00 & -0.03 & 0.08 & -0.09 & 0.03 & 0.05 & 0.28 & -0.02 & $-0.55 *$ & -0.33 \\
\hline PC2 & 0.04 & 0.09 & 0.08 & -0.14 & 0.02 & $-0.53 *$ & -0.21 & -0.30 & -0.41 & $-0.55 *$ \\
\hline \multicolumn{11}{|c|}{ SPEI } \\
\hline PC1 & -0.05 & 0.00 & -0.02 & $-0.21 *$ & -0.06 & -0.15 & 0.25 & -0.11 & $-0.68 *$ & $-0.56 *$ \\
\hline PC2 & -0.00 & -0.01 & 0.07 & -0.08 & -0.01 & $-0.75^{*}$ & -0.41 & $-0.50 *$ & -0.43 & $-0.81 *$ \\
\hline PC3 & -0.02 & -0.02 & 0.04 & $-0.21 *$ & 0.01 & -0.01 & 0.09 & 0.13 & -0.21 & -0.32 \\
\hline PC4 & $-0.21 *$ & -0.15 & -0.09 & $-0.20 *$ & -0.06 & 0.05 & 0.27 & -0.10 & -0.30 & -0.16 \\
\hline PC5 & 0.00 & 0.03 & 0.03 & -0.01 & 0.03 & -0.25 & -0.16 & -0.19 & -0.42 & -0.05 \\
\hline
\end{tabular}




\section{Figure captions}

Figure 1. Topographic map showing the location of the meteorological stations across Bolivia: precipitation (white circles), temperature (black circles).

Figure 2: Examples of drought periods identified based on a $20 \%$ threshold $(-0.84)$ from the 3month SPI and the SPEI series.

Figure 3: Evolution of the 3-, 6-, 12- and 24-month SPI and SPEI from the regional series for Bolivia. The difference between the mean SPI and SPEI series obtained from the same 16 stations is shown.

Figure 4: Variance explained by the principal components obtained from the precipitation and climatic balance series, and the number of components selected.

Figure 5. Spatial distribution of the principal component loadings for the series of precipitation and climatic balance.

Figure 6. Evolution of the 3-, 6-, 12- and 24-month SPI from the series representing PC1 and PC2.

Figure 7. Evolution of the 3-, 6-, 12- and 24-month SPEI from the series representing PC1, PC2, PC3, PC4 and PC5.

Figure 8: Magnitude of change in the annual (12-month) and seasonal (3-month) SPEI and SPI (in colors). The symbols indicate the significance of trends for each meteorological station.

Figure 9. Relationship between the magnitude of change in the SPI and SPEI (in z-units) for the various stations at the annual (12-month) and seasonal (3-month) time scales.

Figure 10: Spatial distribution of change in the duration and magnitude of drought events. The symbols indicate the significance of trends for each meteorological station.

Figure 11: Relationship between the observed change in the magnitude (z-units) and duration (months) of drought events based on the SPI and SPEI series for each station.

Figure 12: Relationship between the observed magnitude of change in the annual SPEI and SPI for each station (in z-units), and the observed change in the duration (months) and magnitude (z-units) of the drought events. 


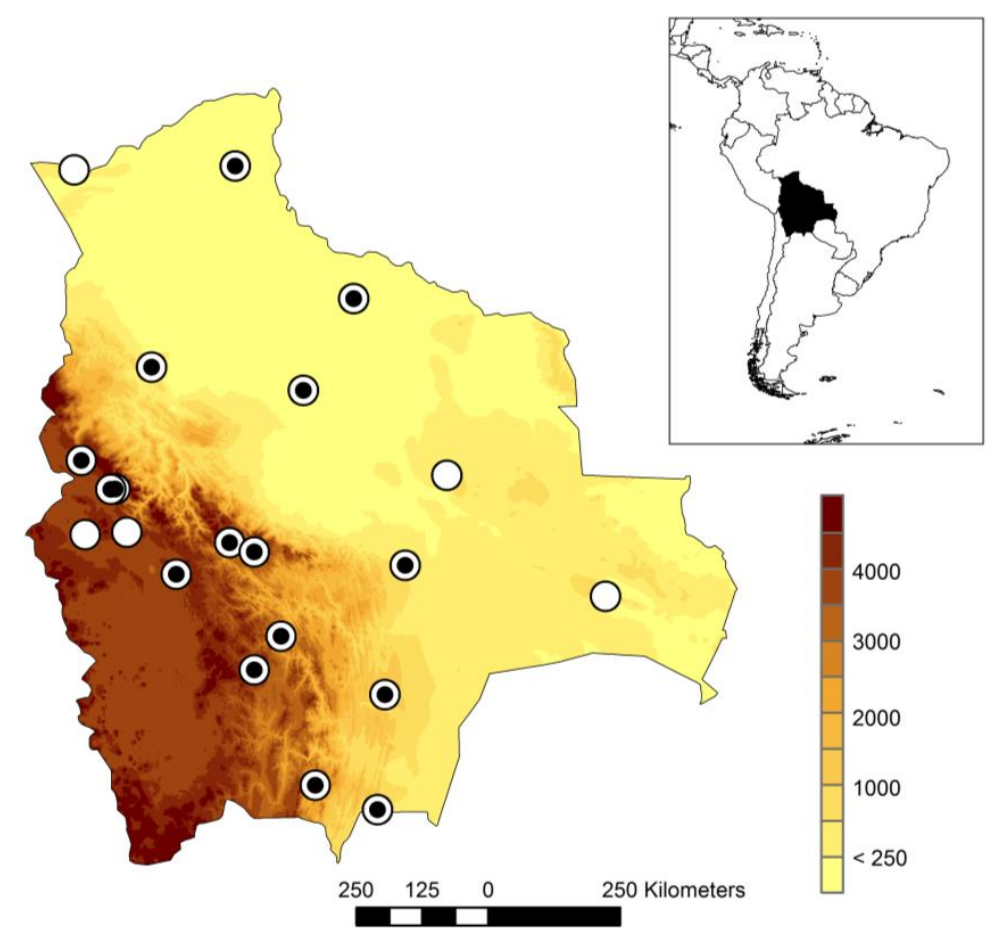

Figure 1. Topographic map showing the location of the meteorological stations across Bolivia: precipitation (white circles), temperature (black circles). 


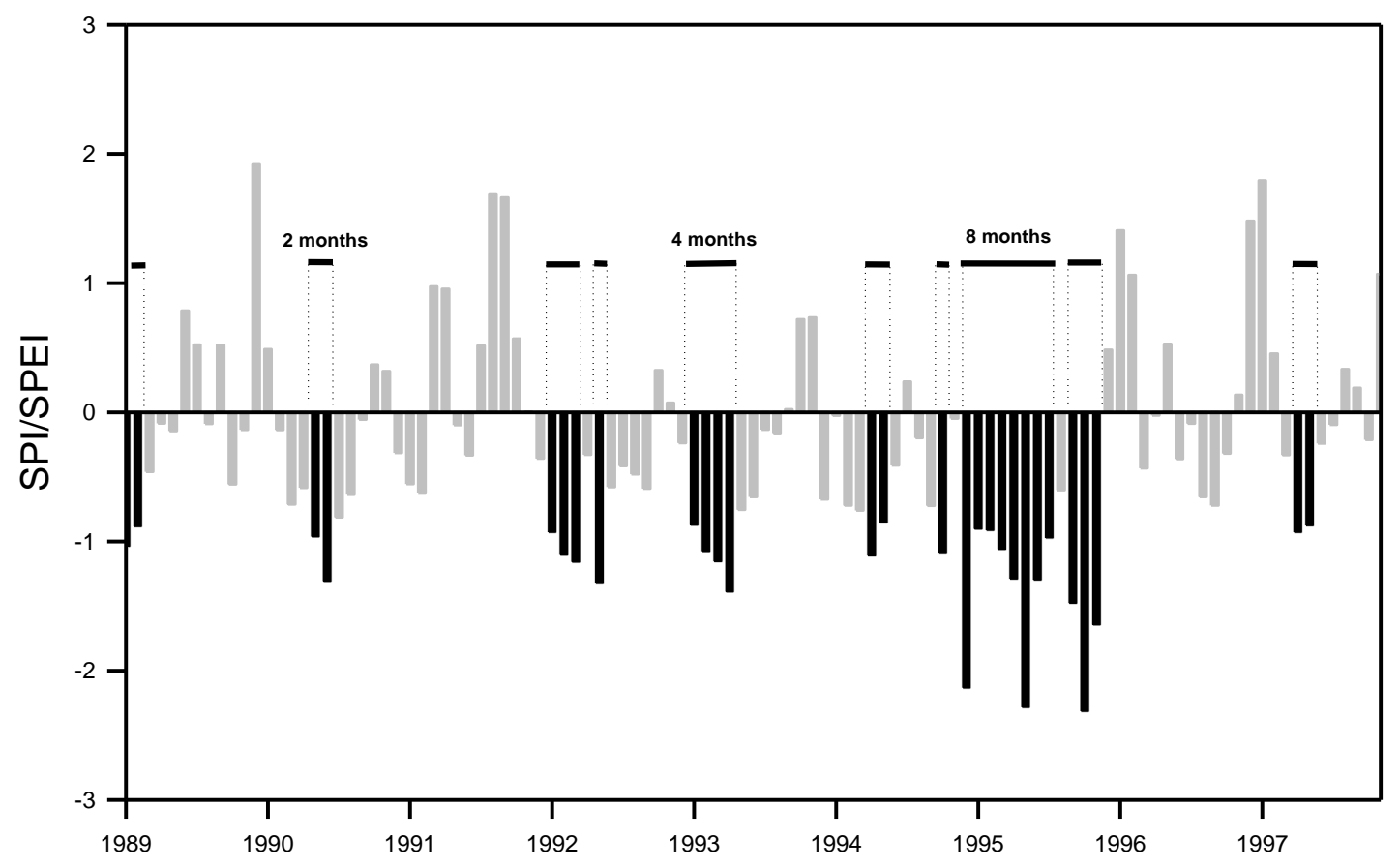

Figure 2: Examples of drought periods identified based on a $20 \%$ threshold (-0.84) from the 3month SPI and the SPEI series. 

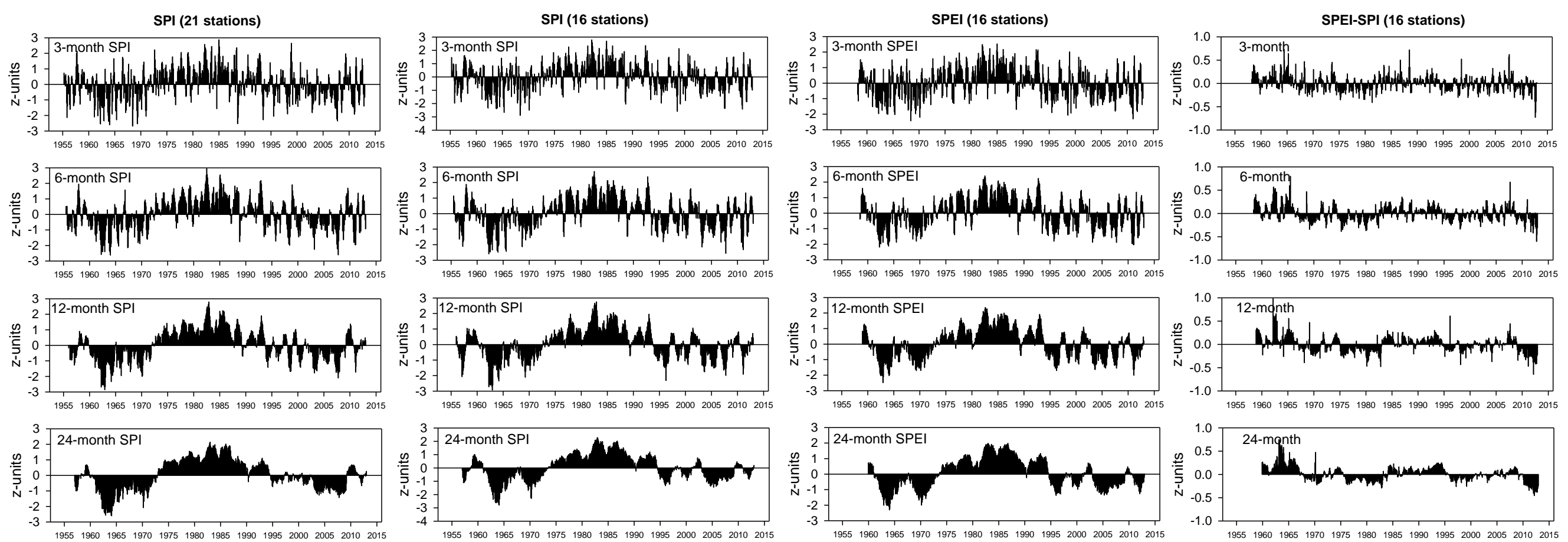

Figure 3: Evolution of the 3-, 6-, 12- and 24-month SPI and SPEI from the regional series for Bolivia. The difference between the mean SPI and SPEI series obtained from the same 16 stations is shown. 

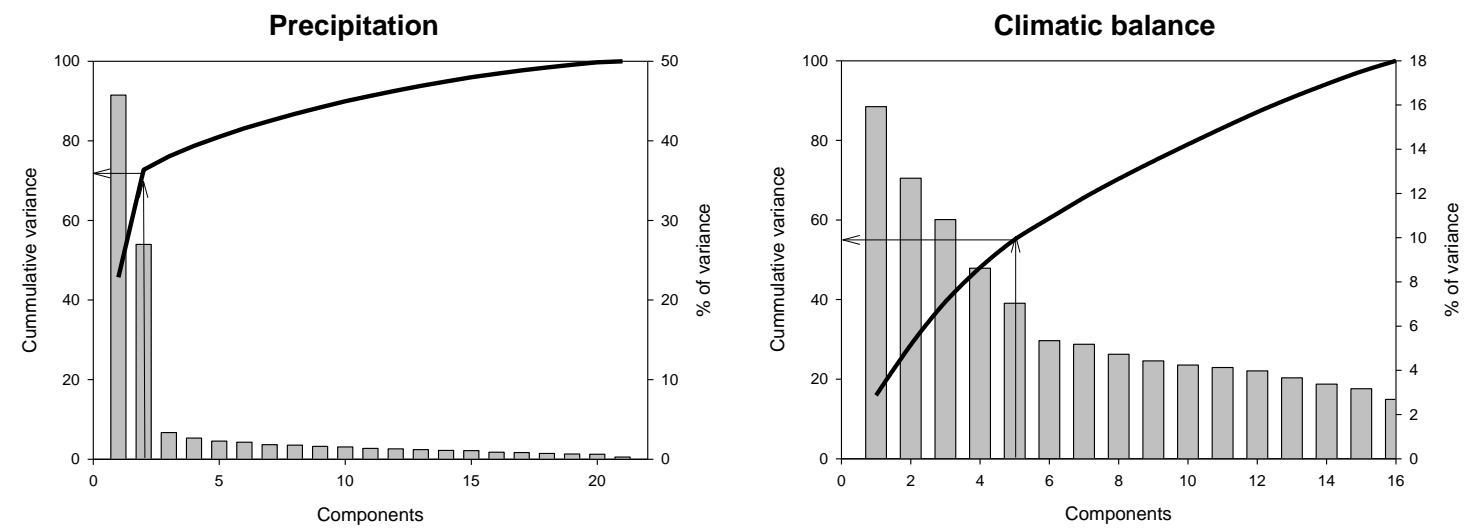

Figure 4: Variance explained by the principal components obtained from the precipitation and climatic balance series, and the number of components selected. 


\section{Precipitation}
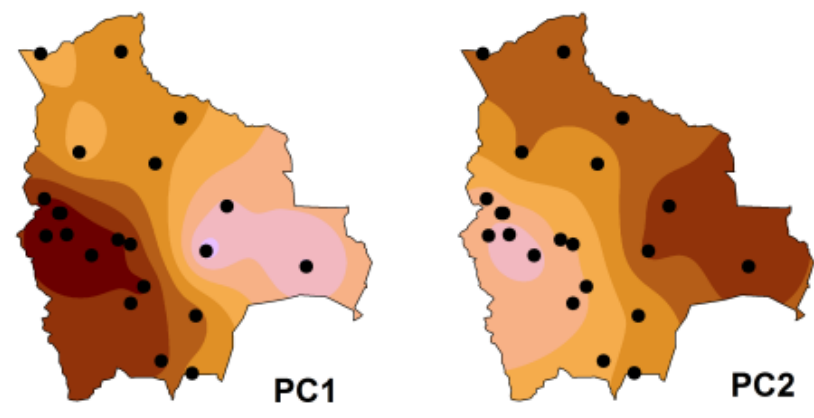

\section{Climatic balance}
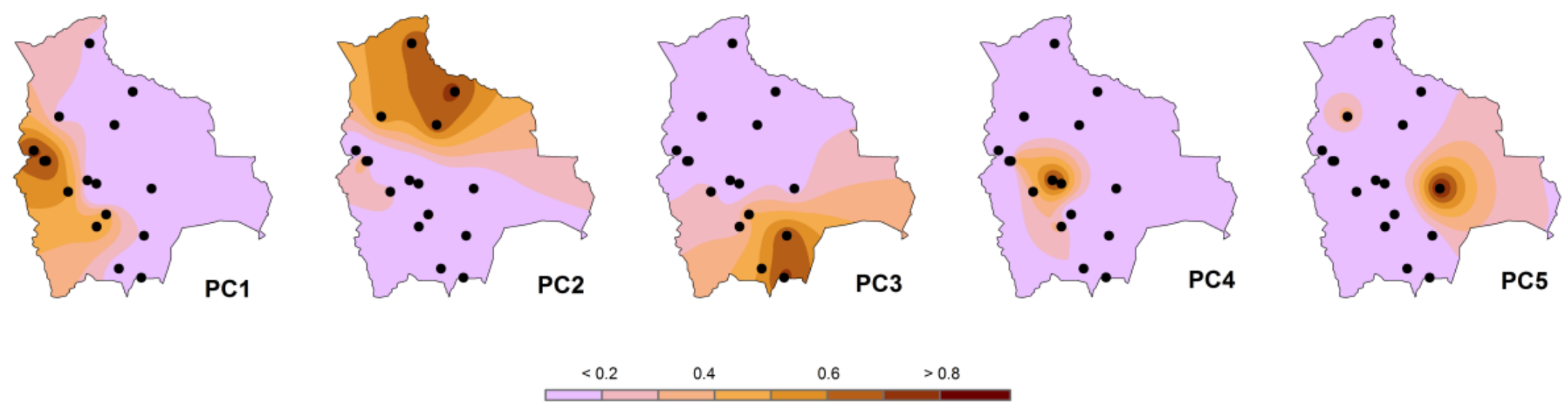

Figure 5. Spatial distribution of the principal component loadings for the series of precipitation and climatic balance. 
PC 1

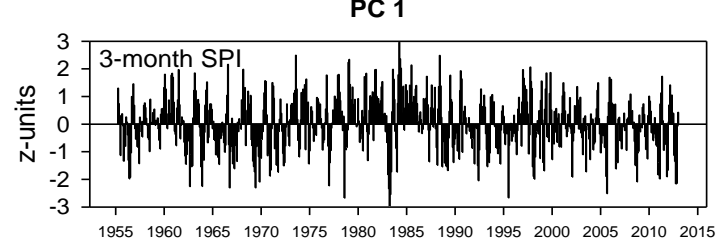

(2-month SPI

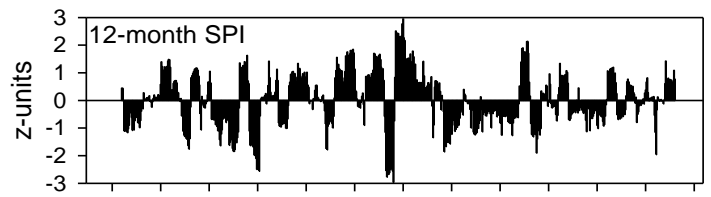

$19551960196519701975 \quad 198019851990 \quad 1995 \quad 2000 \quad 2005 \quad 2010 \quad 2015$

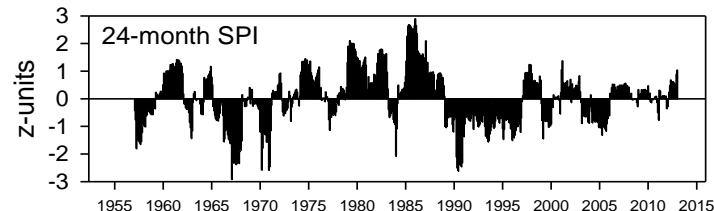

PC 2
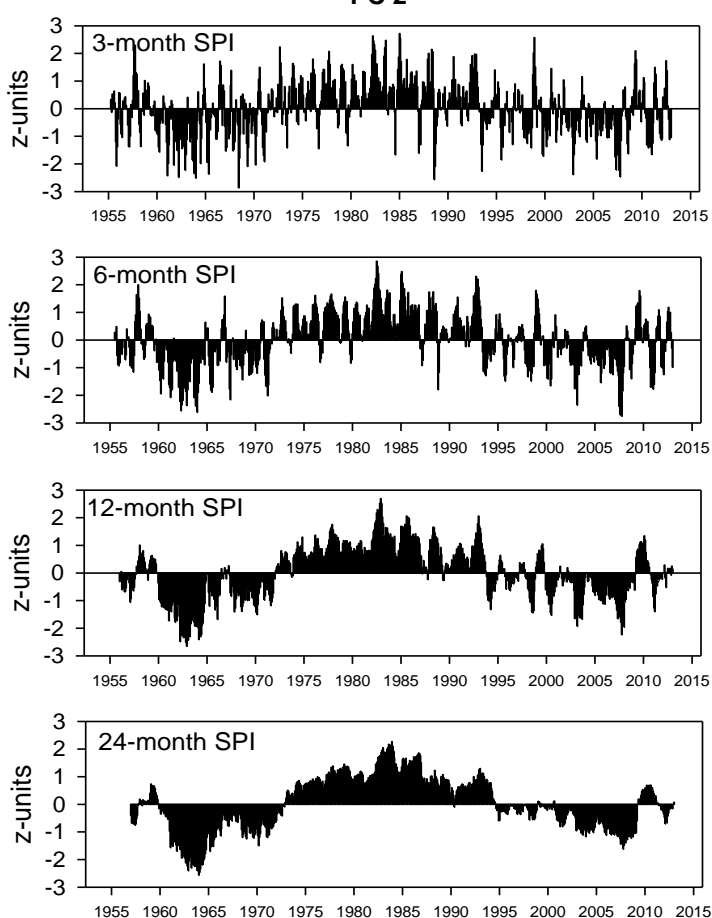

Figure 6. Evolution of the 3-, 6-, 12- and 24-month SPI from the series representing $\mathrm{PC} 1$ and $\mathrm{PC} 2$. 


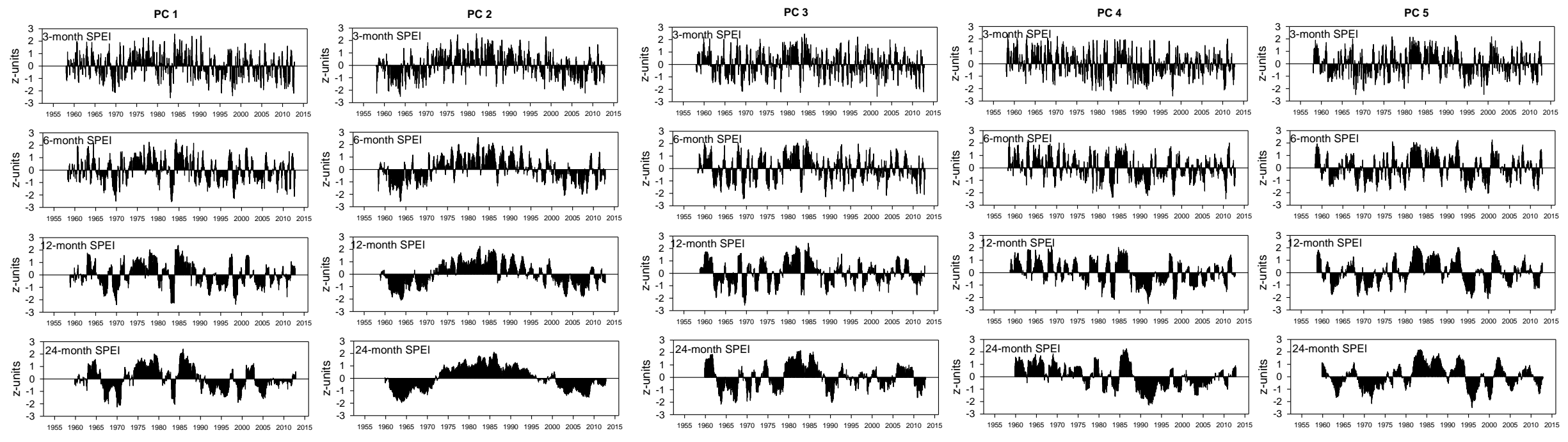

Figure 7. Evolution of the 3-, 6-, 12- and 24-month SPEI from the series representing PC1, PC2, PC3, PC4 and PC5. 
SPI
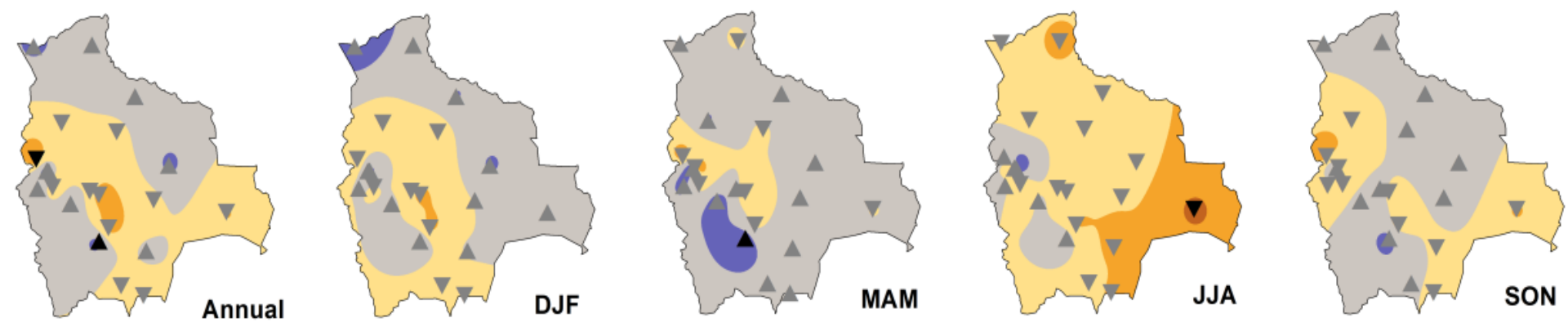

\section{SPEI}
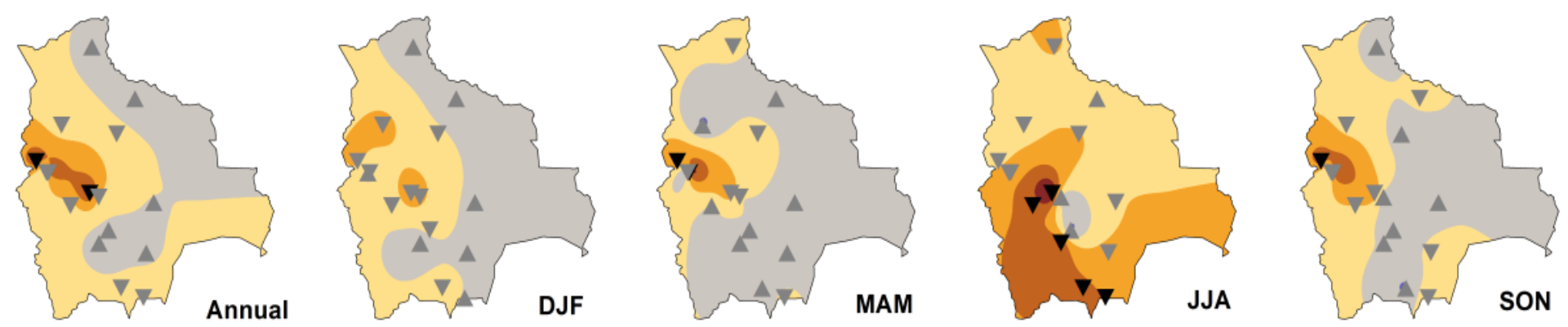

Trend significance:

Magnitude of change (z-units/decade)

A Positive (n.s.) $\boldsymbol{\nabla}$ Negative $(p<0.05)$

$\Delta$ Positive $(p<0.05) \nabla$ Negative $(n \leq s)$

$\begin{array}{cccc}<-0.3 \quad-0.1 & 0.1 \quad>0.3\end{array}$

Figure 8: Magnitude of change in the annual (12-month) and seasonal (3-month) SPEI and SPI (in colors). The symbols indicate the significance of trends for each meteorological station. 

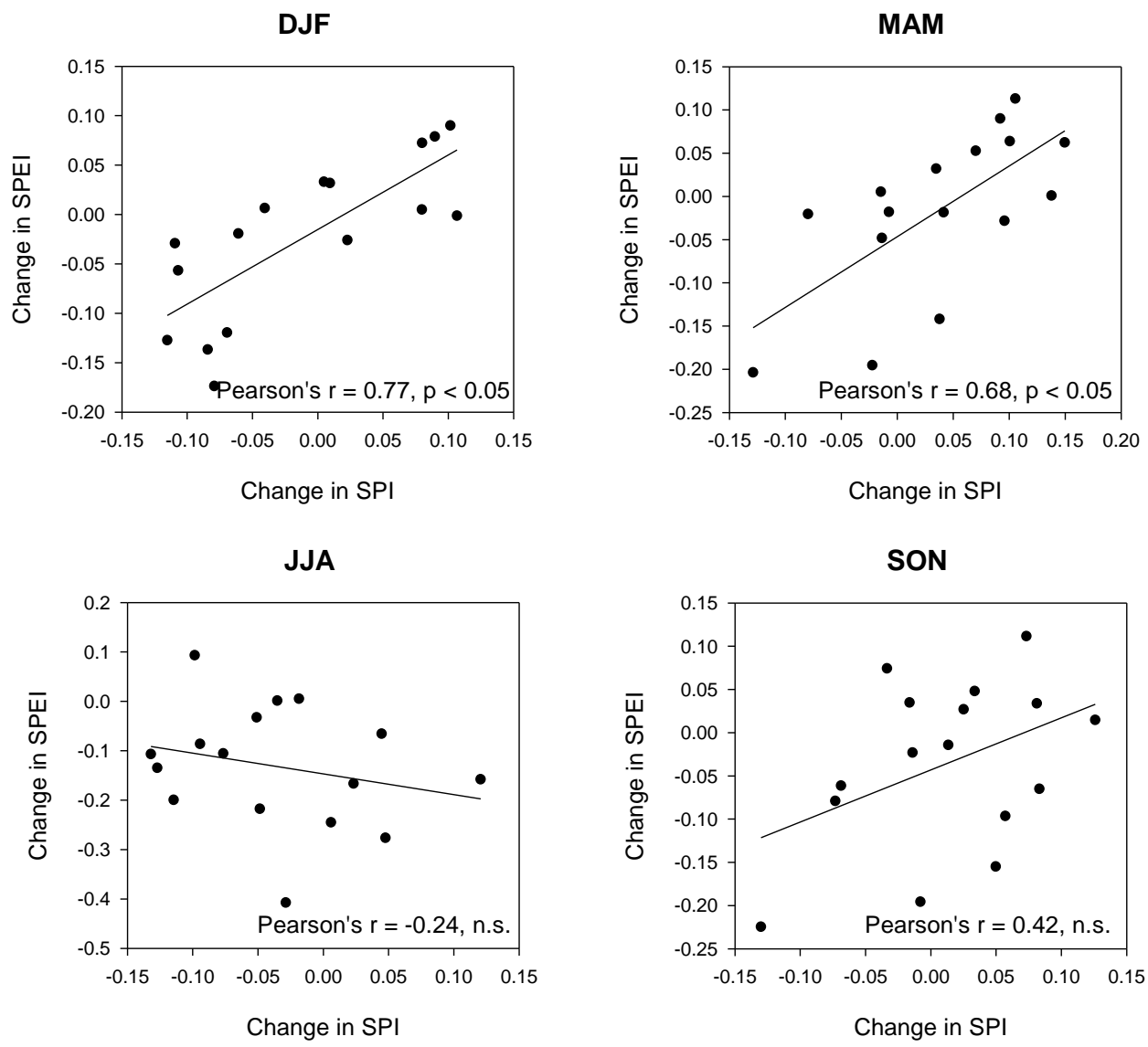

Annual

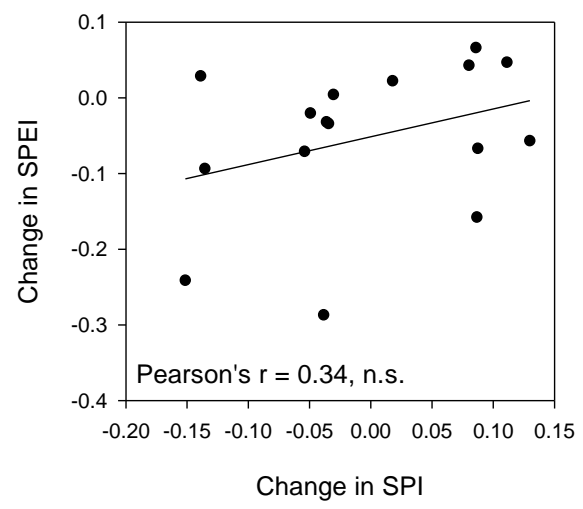

Figure 9. Relationship between the magnitude of change in the SPI and SPEI (in zunits) for the various stations at the annual (12-month) and seasonal (3-month) time scales. 


\section{SPI}
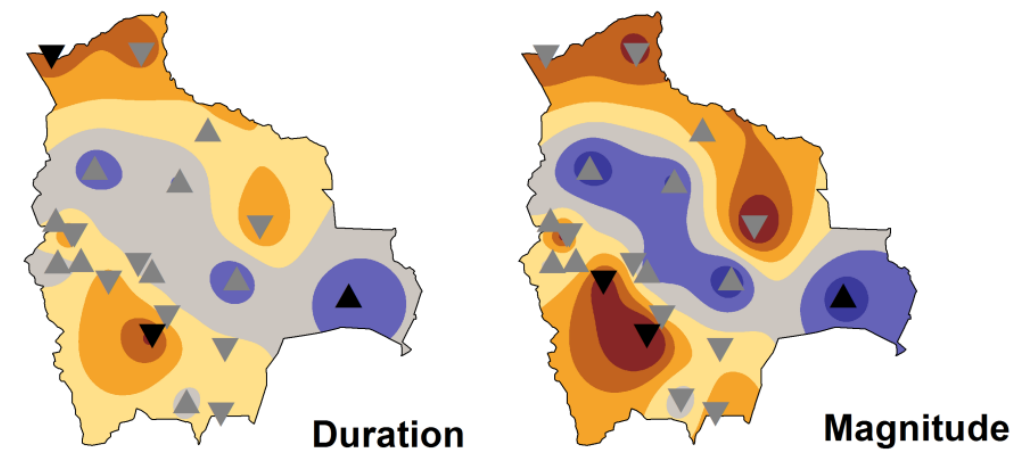

\section{SPEI}
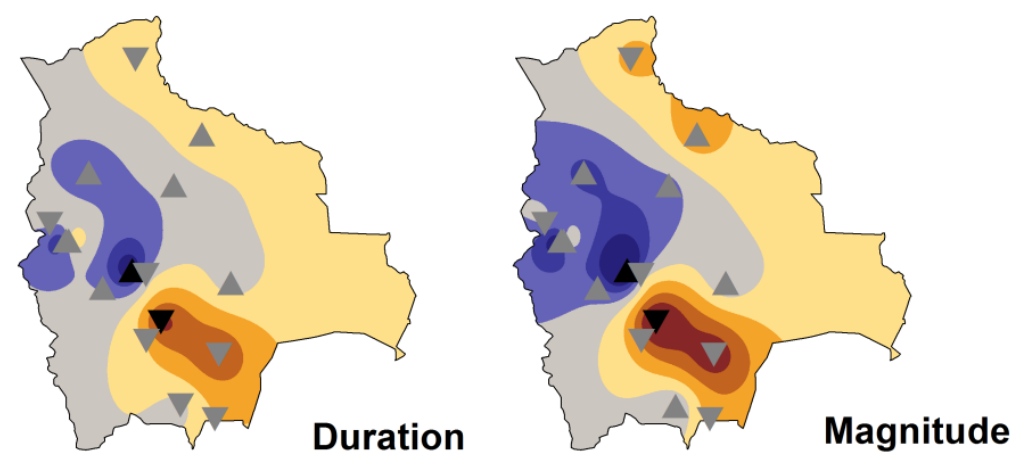

Trend significance:

$\Delta$ Positive (n.s.)

$\Delta$ Positive $(p<0.05)$

$\nabla$ Negative $(p<0.05)$

Negative (n.s.)

\section{Magnitude of change (z-units-months/decade)

$\begin{array}{llll}<-0.3 & -0.1 & 0.1 & >0.3\end{array}$

Figure 10: Spatial distribution of change in the duration and magnitude of drought events. The symbols indicate the significance of trends for each meteorological station. 
SPI

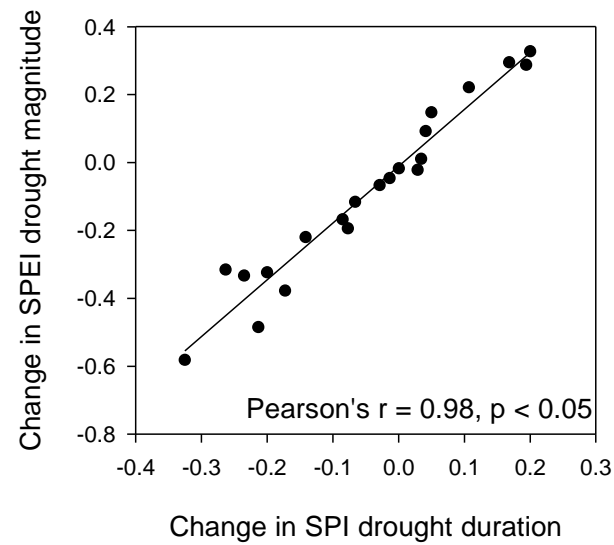

SPEI

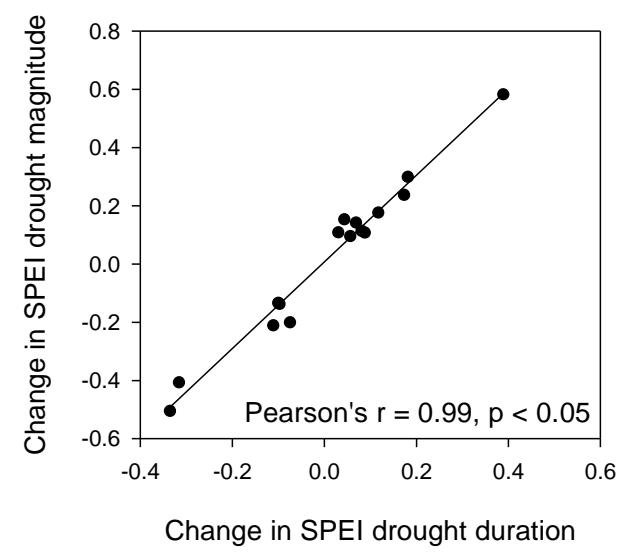

Figure 11: Relationship between the observed change in the magnitude (z-units) and duration (months) of drought events based on the SPI and SPEI series for each station. 
A)
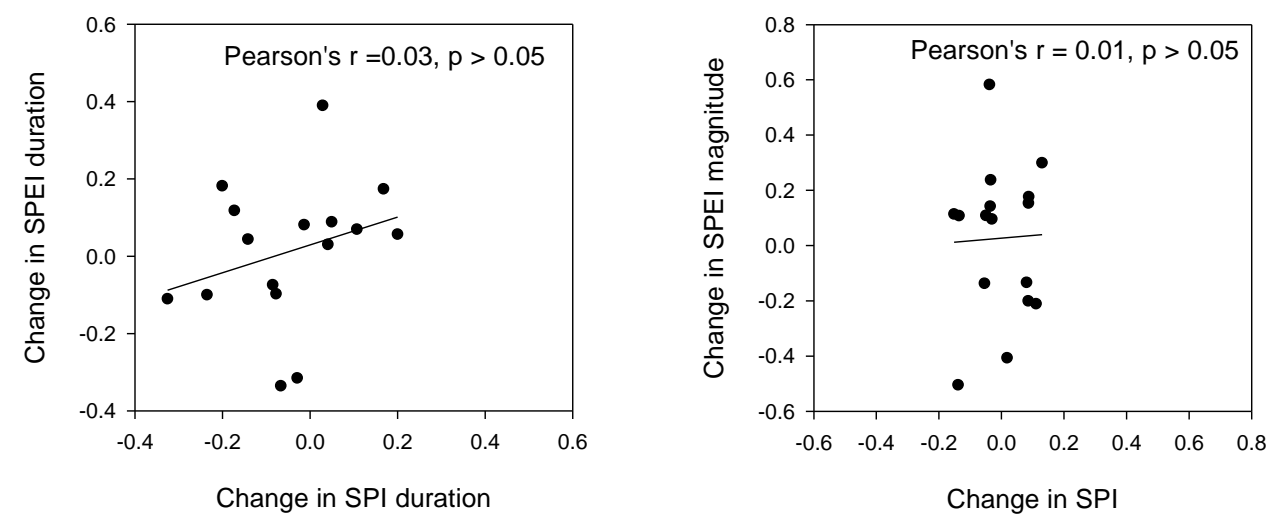

B)
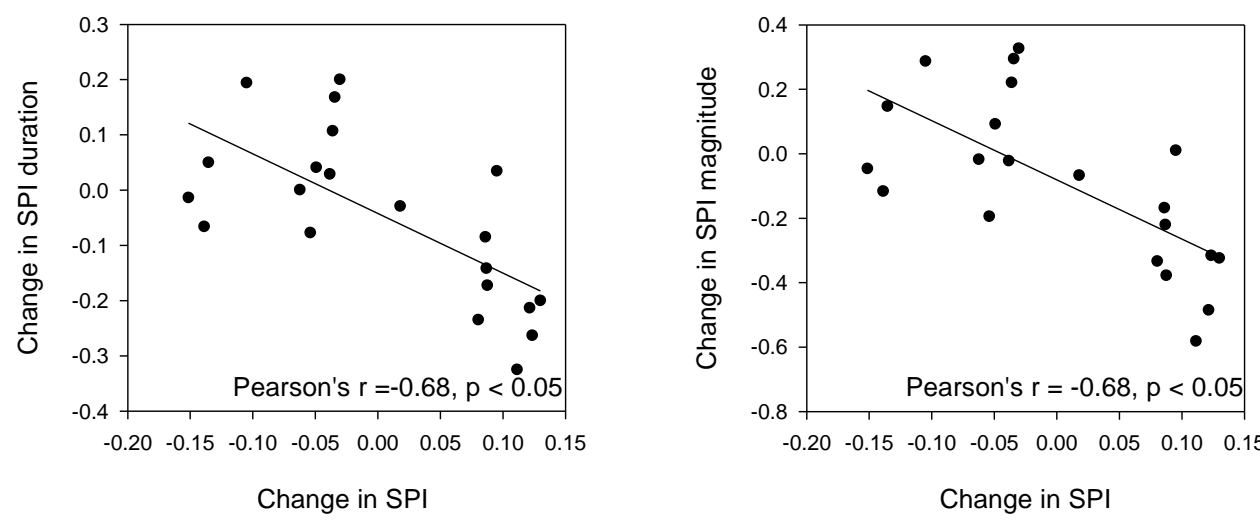

SPEI
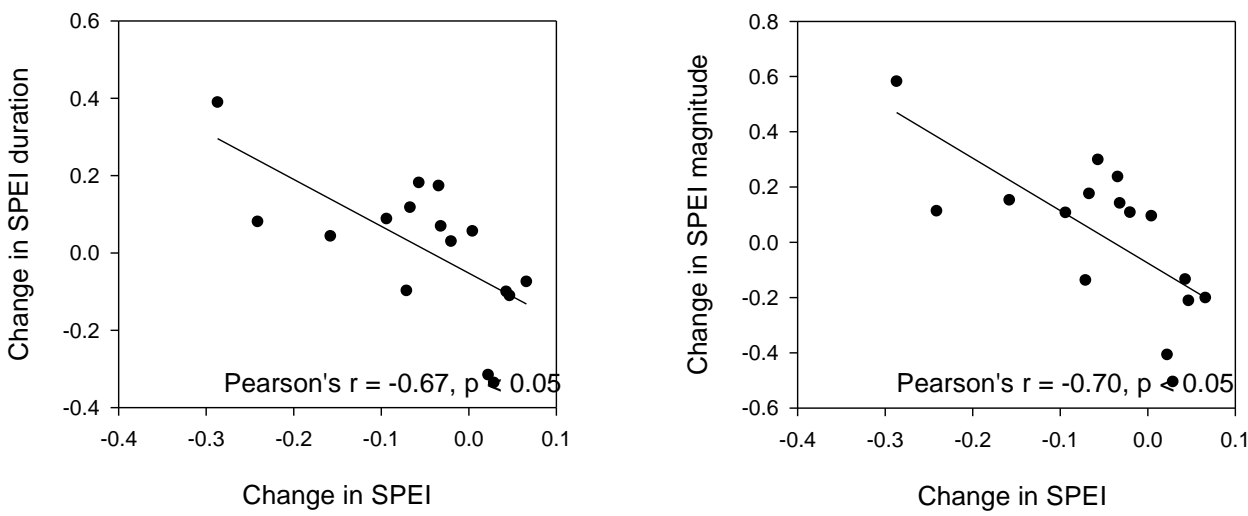

Figure 12: Relationship between the observed magnitude of change in the annual SPEI and SPI for each station (in z-units), and the observed change in the duration (months) and magnitude (z-units) of the drought events. 